Journal of Sustainable Development of Transport and Logistics

journal home page: https://jsdtl.sciview.net

Dhahri, M., Mezghani, M., \& Rekik, I. (2020). A Weighted Goal Programming model for

Storage Space Allocation problem in a container terminal. Journal of Sustainable

Development of Transport and Logistics, 5(2), 6-21. doi:10.14254/jsdtl.2020.5-2.1.

\title{
A Weighted Goal Programming model for Storage Space Allocation problem in a container terminal
}

\author{
Maryam Dhahri *, Mouna Mezghani **(D), Ines Rekik ***(D) \\ * OLID Research Unit, University of Sfax, \\ Road of Aeroport Km 0.5, Sfax, 3029, Tunisia \\ maryam.dahri@yahoo.fr \\ ${ }^{* *}$ OLID Research Unit, University of Sfax, \\ Road of Aeroport Km 0.5, Sfax, 3029, Tunisia \\ mounamezghani@yahoo.ca \\ ${ }^{* * *}$ OLID Research Unit, University of Sfax, \\ Road of Aeroport Km 0.5, Sfax, 3029, Tunisia \\ ines.rekik.86@gmail.com
}

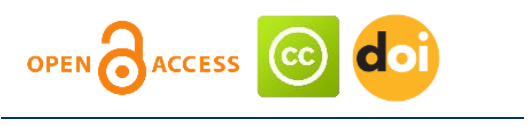

Article history:

Received: September 05, 2020

1st Revision: September 25, 2020

Accepted: November 12, 2020

DOI:

10.14254/jsdtl.2020.5-2.1

\begin{abstract}
Storage Space Allocation Problem (SSAP) is defined as the temporary assignment of unloading/loading containers to the storage blocks during a planning period with the aim of balancing the workload between the blocks. Despite the widespread literature on this topic, several previous studies neglected the practical and implementation aspect of their solutions. The aim of this paper is to formulate and solve the real-life SSAP at the Sfax seaport situated in Tunisia. A Weighted Goal Programming (WGP) based-methodology is proposed as a multi-objective resolution approach. In this proposed approach, three objectives have been accorded including: (i) the balance between the containers unloaded in the blocks, (ii) the balance between the containers unloaded and loaded simultaneously, and (iii) the minimization of the storage cost of the loading/unloading containers for each period. Experimental results show that the proposed approach provides good results and can be effective and practical for the studied Sfax seaport case study.
\end{abstract}

Keywords: Storage Space Allocation Problem, Weighed Goal programming, container terminal, Sfax seaport.

Corresponding author: Maryam Dhahri

E-mail: maryam.dahri@yahoo.fr

This open access article is distributed under a Creative Commons Attribution (CC-BY) 4.0 license. 


\section{Introduction}

The temporary storage of incoming and outgoing containers is one of the most important services to the container terminal. Storage Space Allocation Problem (SSAP) refers to the temporary allocation of incoming containers to the storage blocks in order to balance the workload between blocks (Bazzazi et al., 2009; Dahlin et al., 2014).

The rapid storage and recovery of containers in the blocks is essential for the economic performance of container terminals as well as shipping companies. Therefore, it is necessary to manage the traffic of handling equipment's and consequently the stay and execution time of the ships. The procedure of storing or retrieving a container includes setting time, pickup, moving to the container allocation place and unloading the containers. A container must be assigned to a certain place in the block, it may be necessary to move one or more other containers to access this container which causes increased running time and cost adjustment. Thus, it can be said that the balance between the workload between the blocks is a critical element of the efficiency of the container terminal and it is important to reduce transport costs and shipping time.

A container terminal is composed of three sides: the waterside where vessel operations take place, the yard side for container storage, and the landside where gate operations take place. A simplified layout of a marine container terminal is presented in Figure 1.

Figure 1: A schematic diagram of container terminal

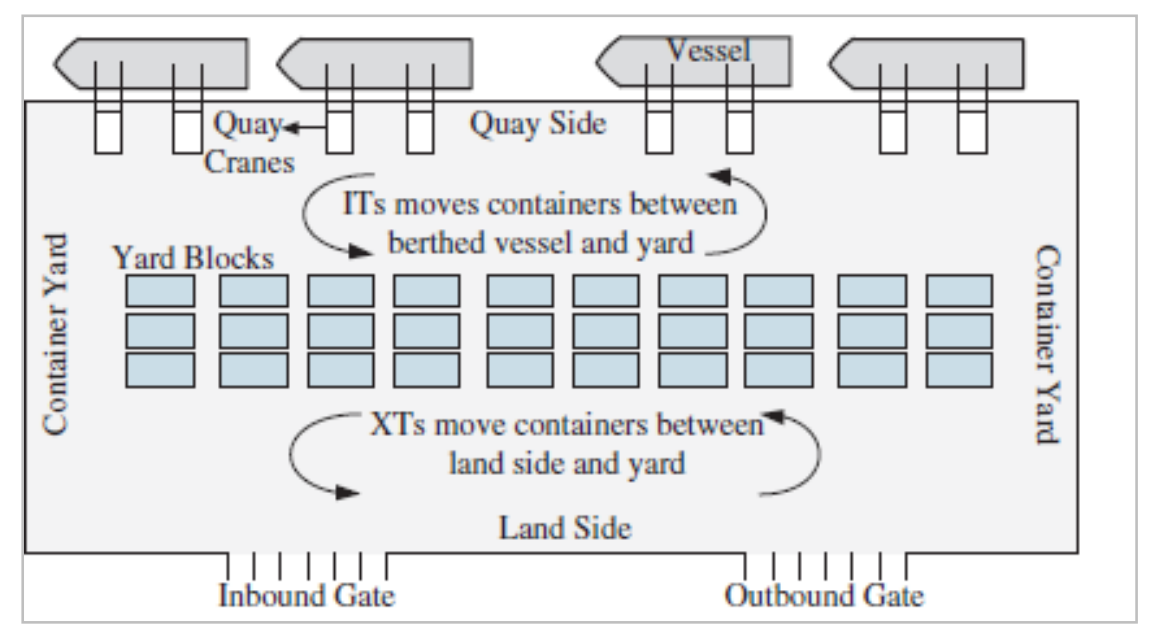

Source: Sharif and Huynh (2013).

Inbound and outbound container operations are different. Inbound containers arrive predictably in large batches at the yard, but depart one by one in an unpredictable order when they are claimed. Outbound containers depart predictably but arrive in a random order. They must be loaded according to a rigid ship storage plan, in order to maintain the stability of the ship and satisfy the loading requirement that is specified by destination and size of containers (Chen and $\mathrm{Lu}, 2012$ ).

The storage area in the terminal is divided into several blocks of containers. Each block (as shown in Figure 2) consists of a number of bays and each bay includes a number of stacks characterized each one by a certain number of tiers which represent the height of the stack (Zhang et al., 2003).

The aim of this paper is to provide a decision making tool to aid port authorities and terminal operators in addressing the storage space allocation problem (SSAP). The main contribution is to propose a Weighted Goal Programming (WGP) formulation for the SSAP, in order to minimize the workload imbalance and the container transport distance. 
Figure 2: Stacking containers in bays and container blocks

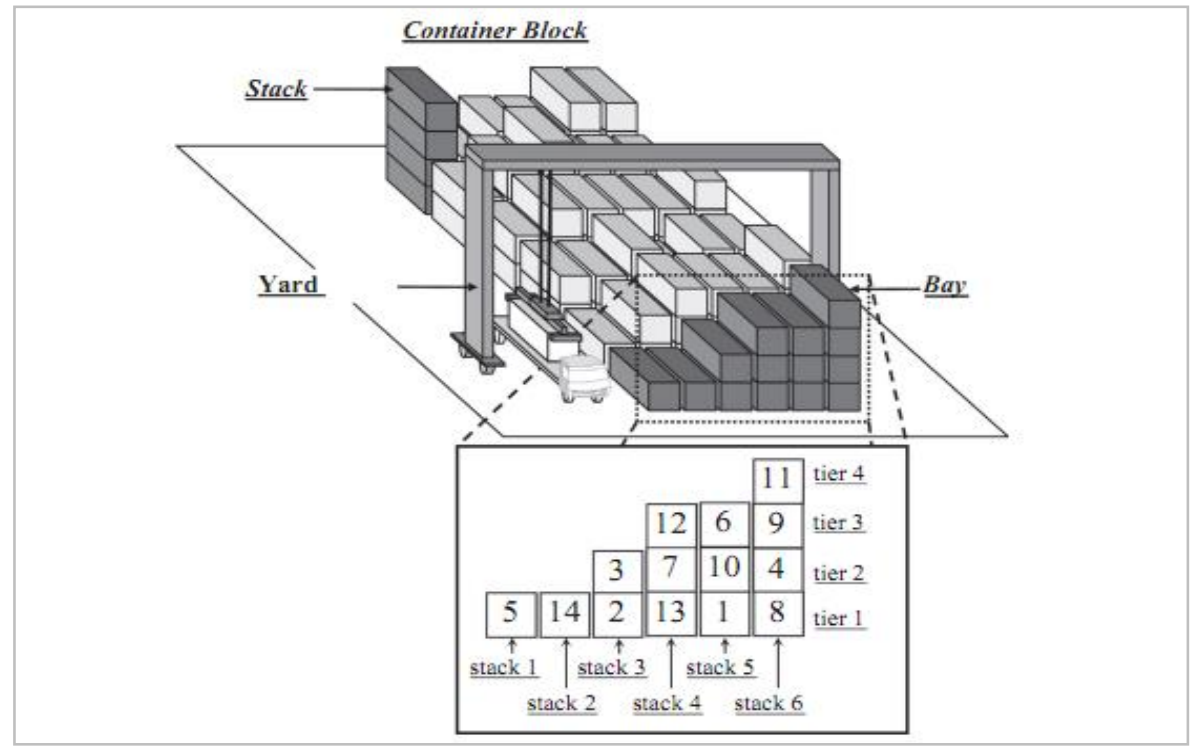

Source: Ting and Wu (2017)

The rest of this paper is organized as follows: a description of the SSAP and related literature is presented in section 2. Section 3 gives a brief overview of Goal Programming and the Sfax seaport case study. The problem is described and formulated in section 4. Implementation and computational results are reported in Section 5 and finally Section 6 covers the conclusion.

\section{Literature review}

Nowadays, marine container terminals play an important role in the international trade. With the continuous development of ports, various types of problems have emerged and attracted increasing attention in recent research including resource allocation problem (Imai et al., 2001), Quay crane scheduling (Lee and Chen, 2010), berth allocation problem (Legato and Mazza, 2001), Human resources management (Legato and Monaco, 2004), stowage and load planning (Imai et al., 2006) and sequencing delivery and receiving operations for storage space cranes (Zhang et al., 2003). Container Terminal Management (CTM) has a significant impact on the performance of the maritime transport systems. The research in this field is very active and has been the focus of many researchers (Vis and Koster, 2003; Steenken and Stahlbock, 2004; Youssef et al., 2005; Sharif and Huynh, 2013; Henesey, 2020). Capacity constraints, lack of adequate decision making tools, congestion, and environmental concerns are some of the major issues facing terminals today.

In container yards (a container yard refers to the storage area in a container terminal), two issues need to be considered by the terminal operators: the design issue and the operational issue. In the design stage, the yard is designed in order to determine the storage space capacity (Zhang et al., 2003). This stage includes the Material Handling Equipment (MHE) selection and the storage yard layout design (Hu et al., 2014).The operational issue concerns the operations that take place in the yard after the design stage. It includes various problems as for example problems related to the storage space assignment to containers (Yan et al., 2011; Hu et al., 2014; Rekik et al., 2015; Hu et al., 2016; Luo \& Mendes, 2016; Woo et al., 2016; Jiang \& Jin, 2017; Tan et al., 2017; Galle et al., 2018; Rekik et al., 2018; Maretto, 2020) and the reshuffling of containers (Ku \& Arthanari, 2016; Covic, 2019).

One of the most important problems, and which is the focus of our study, is related to the storage space allocation (Bazzazi et al., 2009; Yue et al., 2014). In this problem, storage space is allocated to incoming containers.

SSAP is widely used in the literature. For example, Zhang et al. (2003) have decomposed the problem into two levels for each planning horizon. The first level consists on determining the number of containers that can be assigned to each block; while the second level consists on allocating the containers related to each vessel to their dedicated blocks. The objective was to minimize the storage/retrieval time. Bazzazi et al. (2009) have extended the above problem by considering different 
types of containers in the allocation decision such as empty and refrigerated containers. They have solved this problem using Genetic Algorithm. Woo and Kim, (2011) have developed various space reservation strategies and discussed then their impact on the loading operations for outbound containers. In these strategies, containers of the same group must be loaded in the same bay or in adjacent bays. Jiang et al. (2012) have treated the storage yard space allocation for container transshipment movements between mother and feeder vessels within a terminal as well as between terminals. In the reservation of storage space is determined from a dynamic way for different vessels during different shifts (Jiang et al., 2012). Sharif and Huynh (2013) have modeled the SSAP as a bidirectional network constituted by a set of gates, yard blocks and berths. They have proposed also an ant-based control method in order to determine the route for each incoming container. Zhen (2014) has also studied the dynamic SSAP by considering the uncertain demand for freight transportation and the random number of containers that will be loaded onto vessels. Halim et al. (2018) have proposed a bi-level storage pricing model allowing the interaction between a dry port and multiple shippers (seaport). This study is the first that address the problems of dry port's storage pricing. Recently, Luo and Mendes (2016) have proposed a formulation model for the integrated SSAP and the MHE scheduling. This study is the first that combines these two problems. The objective was to minimize ship's berth time. A Genetic Algorithm has been presented for solving large-sized instances.

In sea port logistic field, GP methods are intended to manage container terminal operations. For example, Choirunnisa et al. (2018) have used GP for the optimization of Forecasted Port Container Terminal Performance. Their goals consist on determining the number of documents imported goods letters issued by the customs, minimizing the processing time and the operating costs. Yang et al. (2011) have presented an intermodal transportation network model in order to determine the routing between China and Indian Ocean. They have proposed the application of GP in order to minimize the transportation cost and time. Martel and Aouni (1998) has developed a chance-constrained Goal Programming model to determine the transportation mode (truck, airplane or ocean-ship) and route in order to distribute cargoes.

We observe that the Goal Programming has not been used to solve the SSAP problem. In this research, we propose a WGP formulation to take into account the manager's preferences of Sfax Seaport to fix the goals associated with the objectives.

\section{Goal programming (GP)}

GP is the most widely used approach in the field of multiple criteria decision making that enables the decision maker to incorporate numerous variations of constraints and goals. The first idea of GP technique is initiated in 1955 by Charnes, Copper and Ferguson. According to (Romero, 1986), goal programming is an extension of the linear programming formulation in order to develop mathematical programming models with multiple objectives.

In the scientific literature, GP has been widely used in different fields such as agriculture (Poux \& Aubert, 2018), industry (Jamalnia \& Soukhakian, 2009; Huang et al., 2017; Mokhtari \& Hasani, 2017; Zhuang \& Hocine, 2018), medicine (Oddoye et al., 2009) and logistic (Hildenbrandt et al., 2018; Mirzaee et al., 2018). Regarding methodological development, we note many extensions to the GP model such as: interactive GP, stochastic GP, weighted GP, lexicographical GP, and GP with intervals.

In this paper, we will be concentrated to the weighted GP because the decision maker is more interested to associate priorities to his objectives. In the weighted GP, the weighting of deviational variables at the same priority level shows the relative importance of each deviation.

In its weighted version, the GP model can be written in the following form (Charnes \& Cooper, 1977):

$$
\begin{aligned}
& \text { Minimize } Z=\sum_{i=1}^{p}\left(W^{+}{ }_{i} \delta^{+}{ }_{i}+W^{-}{ }_{i} \delta^{-}{ }_{i}\right) \\
& \text { Subject to the linear constraints: }
\end{aligned}
$$


$\delta_{i}^{+}$and $\delta_{i}^{-} \geq 0 \quad(i=1,2, \ldots, p)$

Where:

$g_{i}$ : The goal associated to the objective i;

$x_{j}$ : Decision variable j;

$a_{i j}$ : Technological parameters related to the system's constraints;

$\rho$ : The coefficient related to the system's constraints;

$\mathrm{c}$ : The available resources;

$\delta_{i}^{+}$and $\delta_{i}^{-}$: Positive and negative deviations from the goal i ;

$w_{i}$ : Relative importance of the goal $i$.

\section{Model formulation}

We present in this section a multi-objective mathematical modeling to solve the SSAP. The WGP will be used to minimize the positive and negative deviations from the goals set by the decision maker of the Sfax sea port.

The sea port of Sfax is founded in 1894. He is one of the major poles for the Tunisian economy thanks to its openness to international trade. This indicates the importance of this port and shows the position of the city of Sfax as a commercial and industrial pole. With its versatile berthing, the port has 13 stations and can actually accommodate 11 ships simultaneously depending on the ship size. The length of the Sfax port quays varies from 110 to 584 meters with drafts of 10.5 meters.

The Sfax seaport has an area of 28 hectares divided between two physically separate shores: the North shore containing various goods and the South shore responsible for the treatment and the storage of containers. The southern shore is composed of an import and an export area. The import area contains 30 non homogeneous blocks. Each block is constituted of 5 bays and each bay contains 4 stacks (the maximum stack height is 3). The logistic currently used for the loading / unloading operations of import/export containers at the port of Sfax consists on assigning machinery (Reach stacker, forklift, Ro-Ro Trucks, Ro- Ro Trailers). The Ro-Ro Trucks with the Ro-Ro Trailers are used to transfer the containers to the storage areas. The reach stackers are then used to manipulate the containers (stacking or retrieval). In this context, the Sfax seaport features 17 forklift, 5 Reach stackers and 4 Ro-Ro Trucks.

Figure 3 shows the current map of the Sfax sea port, the map indicates the allocation of the storage space by specialty logged areas (priority containers, refrigerated containers, goods (TP), goods (shed), etc. ...).

Figure 3: Software Lingo execution solution

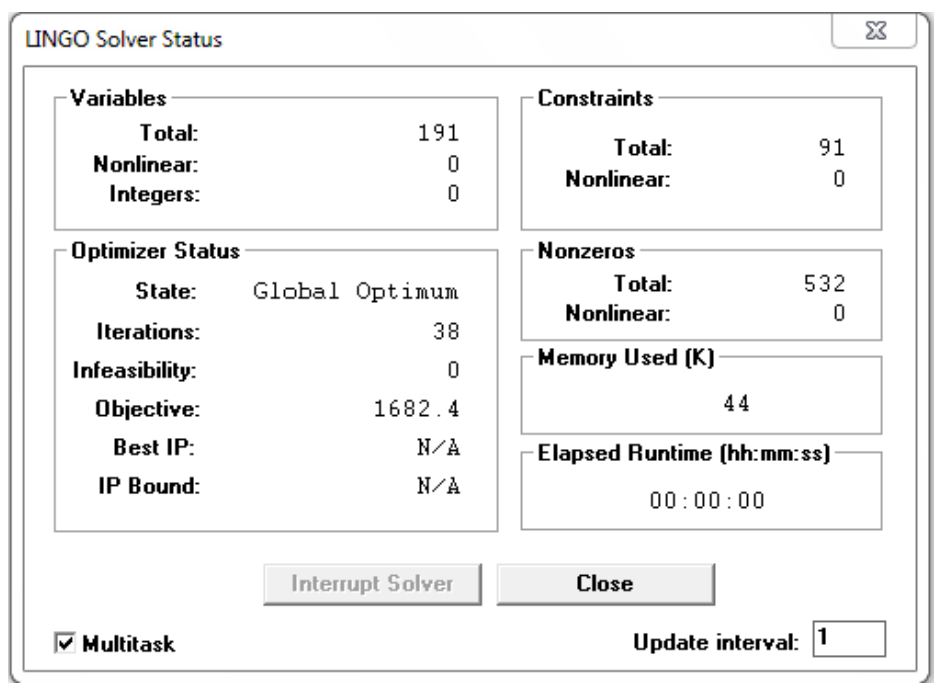




\subsection{Notations}

The definitions were based on the works of Zhang et al. (2003) and Bazzazi et al. (2009):

There are four types of containers:

- Unloading containers: IB containers on ships before they are unloaded and allocated to the storage space $(\mathrm{C} 1)$.

- Container collection container fleet: IB containers already in the storage space waiting to be picked up by customers (C2).

- Sorting earth containers: OB containers before they are carried inside and stored in the storage space (C3).

- Ship loading containers: OB containers already in storage space waiting for ship loading (C4).

Container's flows in a terminal are triggered by the process of arrival of the ship. In other words, the distribution of the berth where the ship is docked, the stowage plan and the sequences for unloading and loading of the ship's containers are clearly determined before the vessel's arrival.

\subsection{Assumptions}

The SSAP is formulated as a mathematical programming model based on the following hypotheses:

1. Only C1 and C2 IB containers are considered.

2. There are sufficient resources (YC, QC, XT and IT) to manage the workload considered in the container terminal.

3. The containers are of different types and sizes. Thus, the workload related to each type of container is determined by the number of these types of containers.

4. Specific blocks are reserved in advance for specific types of containers.

5. Loading and unloading containers are not mixed in the same block and in the same period.

6. Containers are stored respecting the constraint of the compatibility of the size. All containers stored in the same block must have the same dimension.

\subsection{Setting parameters}

$B: \quad$ The total number of blocks in the storage space with $i \in[1,2 \ldots, B]$.

$T: \quad$ The total number of planning periods in the planning horizon, $T=3$.

$R: \quad$ The types of containers.

$C_{\mathrm{i}}: \quad$ The capacity of the storage block $\mathrm{i}, 1 \leq i \leq B$.

$C_{s} \quad$ The storage cost of containers.

$M$ : $\quad$ Large arbitrary positive number.

$D_{\mathrm{tkr}}$ : The expected number of containers (C1) of type $r$ discharged from vessels in the period to be picked up by customers in period $t+k, 1 \leq t \leq T, 0 \leq K \leq T-t$.

$\beta_{\text {itr }}$ : The expected number of containers (C1) of type $r$ discharged from ships in period $t$, allocated to block $i$, with an unknown pickup time or a pickup time beyond the planning horizon, $1 \leq$ $t \leq T, 1 \leq i \leq B$.

$\mathrm{P} 0_{\text {itr }}$ : The total number of containers (C2) of type $\mathrm{r}$ arriving at the container terminal in period $\mathrm{t}$ and to be loaded on ships in the period $t+k, 1 \leq t \leq T, 0 \leq k \leq T-t$.

$V_{\text {ir }}$ : The initial inventory of containers of type $\mathrm{r}$ in block $i$, ie the number of $\mathrm{r}$-type of containers in the block $i$ at the beginning of the planning horizon, $1 \leq i \leq B$.

\subsection{Decision variables}

$D_{\text {itkr }}$ : The number of containers (C1) of type $r$ with full information stored in the block $i$, unloaded from ships in period $t$ and be picked up in period $t+k, 1 \leq i \leq B, 0 \leq k \leq T-t$.

$D_{\text {itr }}$ The total number of containers (C1) of type $r$ with a full or partial information stored in the 
block $i$, unloaded in period $\mathrm{t}, 1 \leq i \leq B, 1 \leq t \leq T$.

$P_{\text {itr }}$ : The total number of containers (C2) of type $\mathrm{r}$ stored in the block $i$, to be picked up by the customer in period $\mathrm{t}, 1 \leq i \leq B, 1 \leq t \leq T$.

$V_{\text {itr }}$ : The number of containers ( 1 and $\mathrm{C} 2$ ) of type $\mathrm{r}$ in the block $i$ at the end of period $\mathrm{t}$, $1 \leq i \leq B, 1 \leq t \leq T$.

\subsection{Proposed mathematical model}

By making attention to the notations and the explanations mentioned above, the multi-objective mathematical model proposed, comprises the system's constraints and some constraints associated with each objective expressed in the form of equality using positive and negative deviations, is written as follows:

$$
\operatorname{Min} Z=W_{1}\left(\delta_{1}^{+}+\delta_{1}^{-}\right)+W_{2}\left(\delta_{2}^{+}+\delta_{2}^{-}\right)+W_{3} \delta_{3}^{+}
$$

Subject to:

$$
\begin{aligned}
& \sum_{t=1}^{3}\left[\max \left\{D_{i t r}\right\}-\min \left\{D_{i t r}\right\}\right]+\delta_{1}^{-}-\delta_{1}^{+}=g_{1} \\
& \sum_{t=1}^{3}\left[\max \left\{D_{i t r}+P_{i t r}\right\}-\min \left\{D_{i t r}+P_{i t r}\right\}\right]+\delta_{2}^{-}-\delta_{2}^{+}=g_{2} \\
& C_{s} \times \sum_{t=1}^{3} V_{i t r}-\delta_{3}^{+}=g_{3} \\
& \sum_{i=1}^{B} D_{i t r k}=D_{t r k}, r=1,2, \ldots, R ; k=1,2, \ldots, T-t ; t=1,2, \ldots, T \\
& D_{i t r}=\beta_{i t r}+\sum_{k=0}^{T-t} D_{i t r k}, r=1,2, \ldots, R ; i=1,2, \ldots, B ; t=1,2, \ldots, T \\
& P_{i t r}=\sum_{k=0}^{t-1} D_{i(t-k) r k}+P_{i t r}^{0}, i=1,2, \ldots, B ; t=1,2, \ldots, T ; r=1,2, \ldots, R \\
& V_{i t r}=V_{i(t-1) r}+D_{i t r}-P_{i t r}, i=1,2, \ldots, B ; t=1,2, \ldots, T ; r=1,2, \ldots, R
\end{aligned}
$$

Containers are uniformly distributed between the blocks. Therefore, the first two constraints are used to measure the imbalances in load / unload containers and the total number of containers in the blocks in each planning period, respectively. For example, in constraint (2), the terms "max (.) - min (.)" involves the imbalance between the workload allocation to blocks. The third constraint is used to measure the storage costs of containers for each planning period.

Constraint (4) ensures that the total number of containers (C1) of type $r$ with complete information waiting for the award is the sum of these containers assigned to all blocks.

Constraint (5) ensures that the total number of containers (C1) of type $r$ allocated in block i in period $t$, is the sum of the total number of containers (C1) with complete information, and these containers with unknown start time in the planning horizon.

Constraint (6) indicates that the number of containers (C2) of type $r$ treated in the block $i$ in period $t$, consists of two parts. The first part is related to containers that are transferred during the planning horizon. The second part is that the containers (C2) initially stored in the block i, can be loaded on ships during the period t of the current planning horizon.

Constraint (7) provides that the inventory of blocks in each planning period must not exceed the authorized capacity of the blocks.

\subsection{Conservation in a linear model}

All decision variables are non-negative integer values. The proposed model is non-linear due to the use of function max and min within the constraints associated with the purposes. It can be converted to a linear model used by Zhang et al. (2003). 


$$
\begin{gathered}
A_{t}=\max \left\{D_{i t r}\right\} ; B_{t}=\min \left\{D_{i t r}\right\} \\
C_{t}=\max \left\{D_{i t r}+P_{i t r}\right\} ; D_{t}=\min \left\{D_{i t r}+P_{i t r}\right\}
\end{gathered}
$$

Then the model can be rewritten as the linear integer programming model below:

$$
\text { minimize } \sum_{t=1}^{T}\left[W_{1}\left(A_{t}-B_{t}\right)+W_{2}\left(C_{t}-D_{t}\right]\right.
$$

Subject to (2)-(7)

$$
\begin{gathered}
D_{i t r} \leq A_{t}, i=1,2, \ldots, B ; t=1,2, \ldots, T . \\
D_{i t r} \geq B_{t}, i=1,2, \ldots, B ; t=1,2, \ldots, T . \\
D_{i t r}+P_{i t r} \leq C_{t}, i=1,2, \ldots, B ; t=1,2, \ldots, T . \\
D_{i t r}+P_{i t r} \geq D_{t}, i=1,2, \ldots, B ; t=1,2, \ldots, T .
\end{gathered}
$$

The additional constraints (9) - (12) reflect the new definitions of variables A, B, C and Din this linear integer programming model.

\section{Implementation and results}

\subsection{Input data}

In this experiment, the container storage area in the port of Sfax has: 56 blocks with different capacities which managed by RTGCs of type r, 52 blocks for priority containers (CP) and 4 blocks for refrigerated containers (CF). Each block is constituted of 5 bays and each bay is of 6 rows constituted

\begin{tabular}{|c|c|c|c|c|c|c|c|c|c|c|}
\hline Block (i) & 1 & 2 & 3 & 4 & 5 & 6 & 7 & 8 & 9 & 10 \\
\hline$C_{i}$ & 48 & 60 & 72 & 96 & 120 & 72 & 60 & 120 & 132 & 96 \\
\hline$M$ & & & & & & & & & & \\
\hline
\end{tabular}
each one by 2 levels. To simplify the work, we have considered only 10 blocks where the first six blocks contain $\mathrm{CP}$ and the rest of blocks contain $\mathrm{CF}$.

Table 1 shows the real storage capacity for each of the 10 blocks where the number of stored containers is less than or equal to $\mathrm{C}_{\mathrm{i}}$ with

$$
M=\sum_{i=1}^{10} C_{i}
$$

\section{Table 2: Importance coefficients and goals}

\begin{tabular}{lccc} 
Objective (i) & $\mathbf{1}$ & $\mathbf{2}$ & $\mathbf{3}$ \\
\hline Importance of Coefficient $W_{i}$ & 0.5 & 0.3 & 0.2 \\
Goal $g i$ & 45 & 80 & 2500 \\
\hline
\end{tabular}

Data related to the following container flows are required for each planning horizon: $D_{t k r}, \beta_{i t r}, P_{i t r}^{0}, V_{i r}$ (as shown in Tables 3, 4, 5 and 6). In this experiment, the data are generated based on the distributions of real container flows of Sfax container terminal.

$$
\begin{aligned}
& \sum_{i=1}^{6} C P=468 \\
& \sum_{i=1}^{4} C F=408
\end{aligned}
$$

- C1 containers can be stored in 6 blocks $(i=1,2, \ldots, 6)$, of which 3 are reserved for CP containers and 3 for CF containers.

- C2 containers can be stored in 4 blocks $(i=1,2, \ldots, 4)$, of which 2 for $\mathrm{CP}$ and 2 for CF. 


\begin{tabular}{lccc} 
Table 3: Values of $\boldsymbol{D}_{\boldsymbol{t k r}}$ & & $\mathbf{2}$ & $\mathbf{3}$ \\
Period (t) & $\mathbf{1}$ & 225 & 335 \\
\hline \multirow{3}{*}{$\mathrm{D}_{\mathrm{tkr}}$} & 400 & 440 & 414 \\
& 450 & 460 & 299 \\
\hline
\end{tabular}

\begin{tabular}{|c|c|c|c|c|c|c|}
\hline Block (i) & 1 & 2 & 3 & 4 & 5 & 6 \\
\hline \multirow{3}{*}{$\beta_{\mathrm{itr}}$} & 30 & 35 & 44 & 65 & 79 & 43 \\
\hline & 33 & 40 & 42 & 50 & 90 & 55 \\
\hline & 29 & 39 & 50 & 55 & 77 & 59 \\
\hline
\end{tabular}

Table 5: Number of initial containers C2

\begin{tabular}{lcccc} 
Block (i) & $\mathbf{7}$ & $\mathbf{8}$ & $\mathbf{9}$ & $\mathbf{1 0}$ \\
\hline \multirow{3}{*}{$\mathrm{P}{ }_{\text {itr }}$} & 25 & 41 & 44 & 30 \\
& 13 & 39 & 32 & 26 \\
\end{tabular}

\section{Table 6: Values of the inventory $V_{\text {ir }}$}

\begin{tabular}{lccccccccccc}
$\begin{array}{l}\text { Block } \\
\text { (i) }\end{array}$ & $\mathbf{1}$ & $\mathbf{2}$ & $\mathbf{3}$ & $\mathbf{4}$ & $\mathbf{5}$ & $\mathbf{6}$ & $\mathbf{7}$ & $\mathbf{8}$ & $\mathbf{9}$ & $\mathbf{1 0}$ \\
\hline & 18 & 25 & 28 & 31 & 41 & 29 & 35 & 79 & 88 & 66 \\
$\mathrm{~V}_{\text {ir }}$ & 15 & 20 & 30 & 46 & 30 & 17 & 47 & 81 & 100 & 70 \\
& 19 & 21 & 22 & 41 & 43 & 13 & 32 & 96 & 79 & 51 \\
\hline
\end{tabular}

In order to minimize the positive and negative deviations from the goals set by the manager of the port of Sfax, we developed a Goal Programming model to find the optimal solution. The manager focuses on: (1) balancing between the containers unloaded in the blocks; (2) balancing between the containers unloaded and loaded simultaneously; (3) minimizing the cost of storing the loading and unloading containers in each period $t$.

For each of these objectives, the decision maker has fixed the goals $g_{i}(i=1,2,3)$ and the importance coefficients $W_{i}(i=1,2,3)$ for each goal (Table 2).

\subsection{Results and discussion}

The developed model was solved using Lingo software to find the adopted solution. Lingo is a comprehensive tool designed to make building and solving linear, nonlinear and integer optimization models. It is faster, easier and more efficient. It provides a completely integrated package that includes a powerful language for expressing optimization models, a complete environment for building and editing problems, and a set of integrated fast solvers. Due to the large size of the integer programming model, the value of the objective function after 38 iterations is 1682,400 (as shown in Figure 3).

To compare the efficiencies and know the limits of the proposed model, we performed several experiments taking into account the two types of containers used C1 and C2 and we varied then the number of blocks (see appendix).

According to Table 7, the number of loading and unloading containers varies only in blocks 1 and 2 for the CP containers type, and in the block 4 for CF containers type during the three periods. The other blocks are empty. 


\begin{tabular}{|c|c|c|}
\hline Period (t) & Bloc i & $V_{\text {itr }}$ \\
\hline \multirow[t]{10}{*}{ 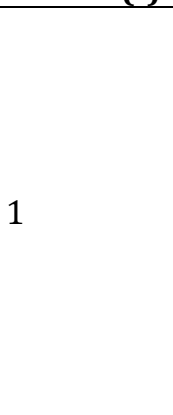 } & 1 & 23 \\
\hline & 2 & 19 \\
\hline & 3 & 0 \\
\hline & 4 & 66 \\
\hline & 5 & 0 \\
\hline & 6 & 0 \\
\hline & 7 & 0 \\
\hline & 8 & 0 \\
\hline & 9 & 0 \\
\hline & 10 & 0 \\
\hline \multirow{10}{*}{2} & 1 & 35 \\
\hline & 2 & 21 \\
\hline & 3 & 0 \\
\hline & 4 & 70 \\
\hline & 5 & 0 \\
\hline & 6 & 0 \\
\hline & 7 & 0 \\
\hline & 8 & 0 \\
\hline & 9 & 0 \\
\hline & 10 & 0 \\
\hline \multirow{10}{*}{3} & 1 & 20 \\
\hline & 2 & 36 \\
\hline & 3 & 0 \\
\hline & 4 & 51 \\
\hline & 5 & 0 \\
\hline & 6 & 0 \\
\hline & 7 & 0 \\
\hline & 8 & 0 \\
\hline & 9 & 0 \\
\hline & 10 & 0 \\
\hline
\end{tabular}

In Table 8, the total number of containers unloaded from two kinds $r$ stored in the blocks varies only in the block 6 for the type of containers CF during the three periods $t, k=1,2,3$ ( $k$ is the number of shift work) and the rest are empty.

\begin{tabular}{|c|c|c|c|}
\hline Period (t) & $\mathbf{K}$ & Bloc i & Ditrk \\
\hline \multirow{18}{*}{1} & \multirow{6}{*}{1} & 1 & 0 \\
\hline & & 2 & 0 \\
\hline & & 3 & 0 \\
\hline & & 4 & 0 \\
\hline & & 5 & 0 \\
\hline & & 6 & 400 \\
\hline & \multirow{6}{*}{2} & 1 & 0 \\
\hline & & 2 & 0 \\
\hline & & 3 & 0 \\
\hline & & 4 & 0 \\
\hline & & 5 & 0 \\
\hline & & 6 & 225 \\
\hline & \multirow{6}{*}{3} & 1 & 0 \\
\hline & & 2 & 0 \\
\hline & & 3 & 0 \\
\hline & & 4 & 0 \\
\hline & & 5 & 0 \\
\hline & & 6 & 335 \\
\hline \multirow{3}{*}{2} & \multirow{3}{*}{1} & 1 & 0 \\
\hline & & 2 & 0 \\
\hline & & 3 & 0 \\
\hline
\end{tabular}




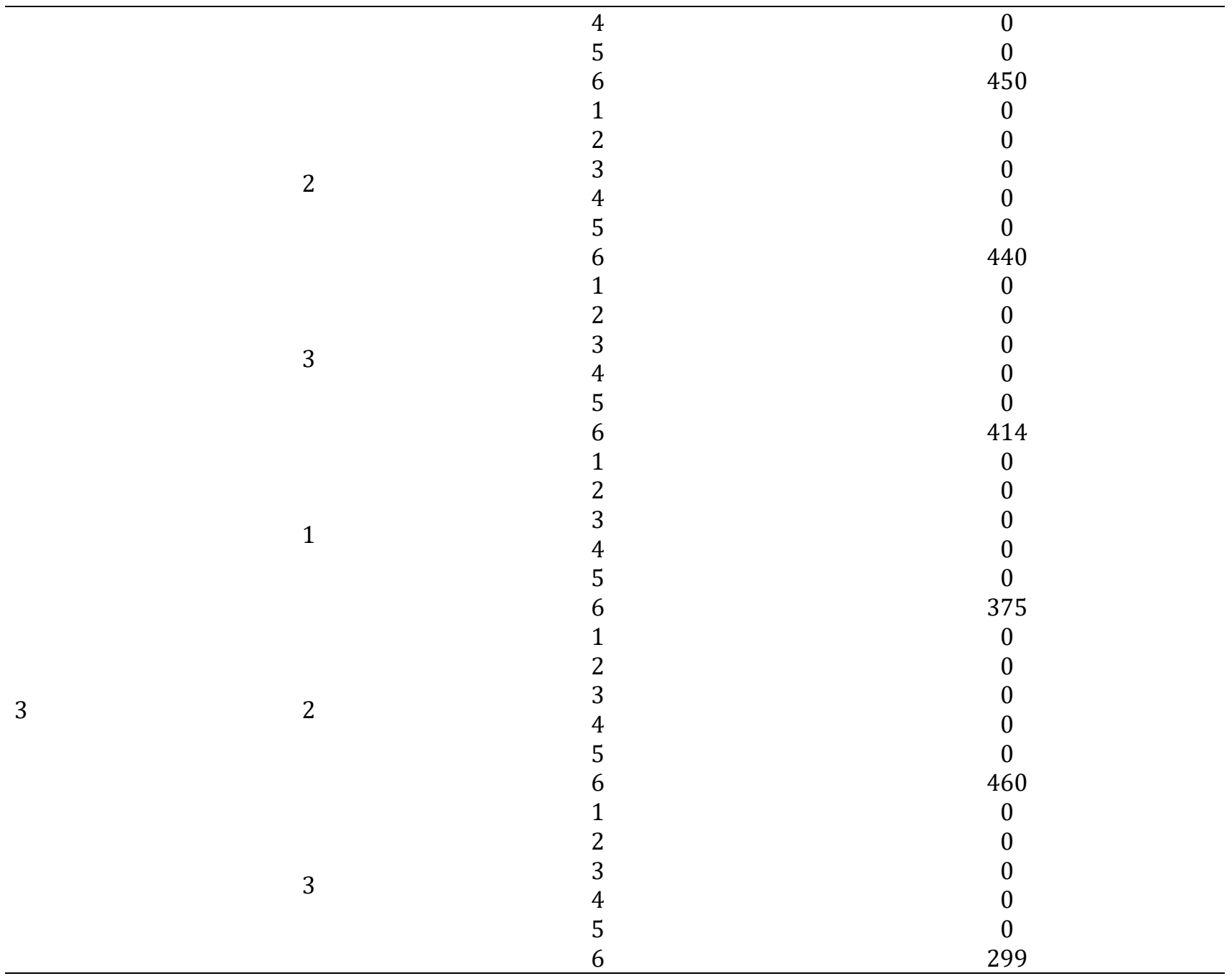

In Table 9, it is noted that the number of loaded containers by customers and that are stored in the blocks 7, 8, 9 and 10 varies from one block to another during the three planning periods.

\section{Table 9: Number of $\mathrm{C} 2$ containers in 4 blocks during the period $(\mathrm{t})$}

\begin{tabular}{ccc}
\hline Period (t) & Bloc i & Pitr \\
\hline 1 & & 35 \\
2 & 7 & 47 \\
3 & & 32 \\
1 & 8 & 79 \\
2 & & 81 \\
3 & & 96 \\
1 & 9 & 88 \\
2 & & 100 \\
3 & & 79 \\
1 & 10 & 66 \\
2 & & 70 \\
3 & & 51 \\
\hline
\end{tabular}

We note that when we increase or decrease the number of blocks, or also the values $\mathrm{C} 1$ and $\mathrm{C} 2$ related to the types of containers, the value of the objective function changes. This result indicates that the model is sensitive to the blocks number. Figures 4, 5 and 6 indicate respectively the evolution of the variables found in the number of blocks $(10,6$ and 4 blocks respectively). 
Figure 4: The evolution of variables of containers C1 and C2 for 10 blocks

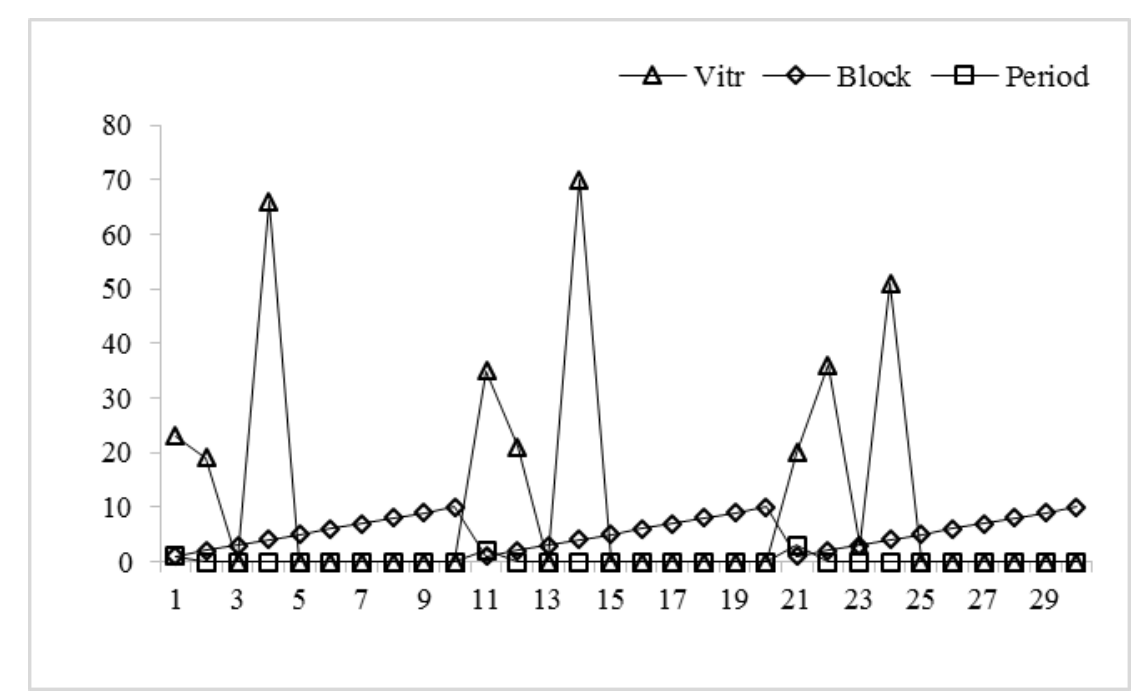

Figure 5: The evolution of variables of containers $\mathrm{C} 1$ in the case of 6 blocks

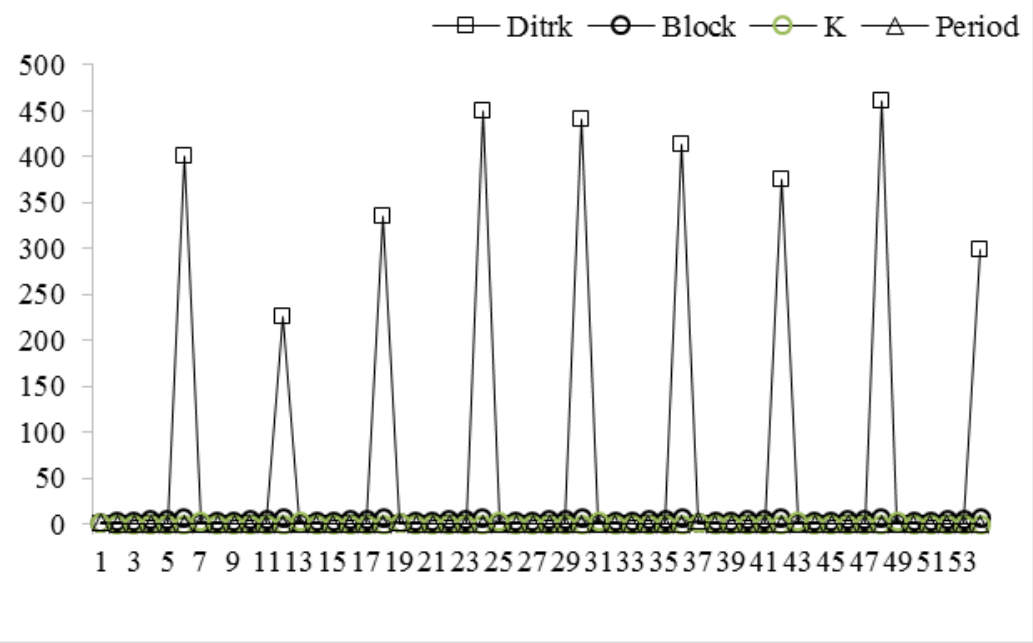

Figure 6: The evolution of variables of containers $C 2$ in the case of blocks 4

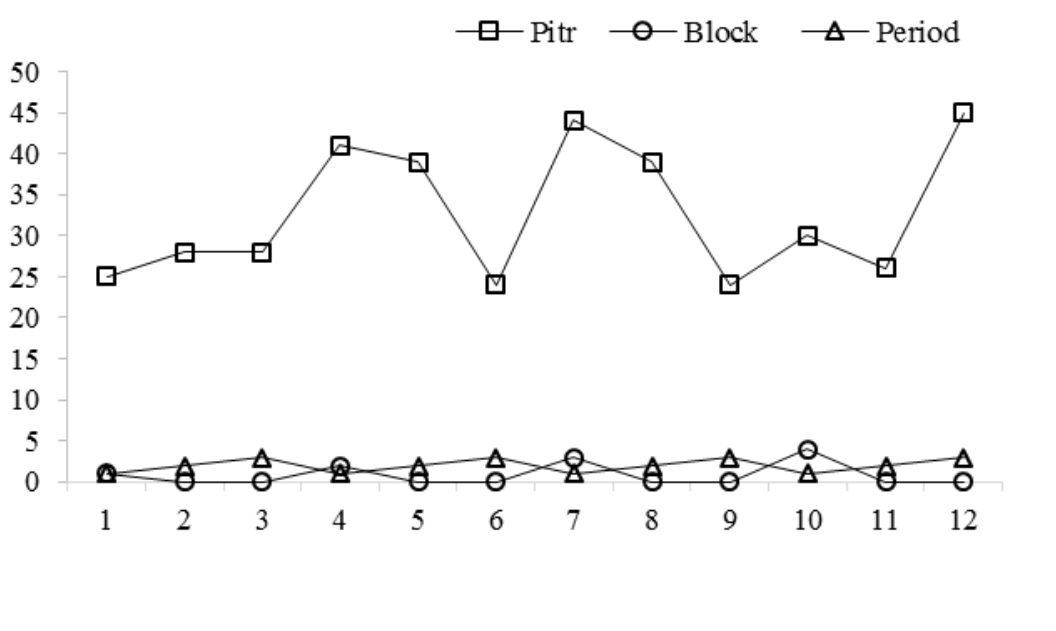




\section{Conclusion}

In this work, we considered the Storage Space Allocation Problem. A brief literature review shows that several models were proposed in order to solve this problem. Nevertheless, these models neglect the decision maker's preferences. We applied the WGP method in order to minimize the positive and negative deviations from the goals set by the manager of the port of Sfax. By using the software Lingo package, the solution determines the total number of containers to be placed in each storage block in each time period so as to balance the workloads among blocks in each period, the unloaded containers in the blocks, and the unloaded and loaded containers simultaneously in order to minimize the cost of storage of unloaded and loaded containers in the blocks during each period $t$.

As a future study, we may try different hierarchical breakdowns related to the Storage Space Allocation Problem so as to improve the solution procedure. With this problem solved, we will start to study the location assignment problem of containers.

\section{Citation information}

Dhahri, M., Mezghani, M., \& Rekik, I. (2020). A Weighted Goal Programming model for Storage Space Allocation problem in a container terminal. Journal of Sustainable Development of Transport and Logistics, 5(2), 6-21. doi:10.14254/jsdtl.2020.5-2.1

\section{References}

Bazzazi, M., Safaei, N., \& Javadian, N. (2009). A genetic algorithm to solve the storage space allocation problem in a container terminal. Computers \& Industrial Engineering, 56(1), 44. doi: 10.1016/j.cie.2008.03.012.

Chen, L., \& Lu, Z. (2012). The storage location assignment problem for outbound containers in a maritime terminal. International Journal of Production Economics, 135(1), 73-80. doi: 10.1016/j.ijpe.2010.09.019.

Choirunnisa, S., Sarno, R., \& Fauzan, A.C. (2018). Optimization of forecasted port container terminal performance using goal programming. In 2018 International Conference on Information and Communications Technology (ICOIACT), 332-336.

Covic, F. (2019). Literature Review on Container Handling in the Yard Area. in Container Handling in Automated Yard Blocks: An Integrative Approach Based on Time Information, F. Covic, Éd. Cham: Springer International Publishing, 47-72.

Dahlin, M.D., Alvisi, L., Ganesh, L., Silberstein, M., Wang, Y., Kapritsos, Mahajan, Kirubanandam, \& Ren, Z. (2014). Robustness in a scalable block storage system. US20140143367A1. https://patentimages.storage.googleapis.com/37/bd/d7/1bb9f38f6bb0f9/US20140143367A1.pd $\mathrm{f}$.

Galle, V., Barnhart, C., \& Jaillet, P. (2018). Yard Crane Scheduling for container storage, retrieval, and relocation. European Journal of Operational Research, 271(1), 288-316. doi: 10.1016/j.ejor.2018.05.007.

Halim, K., Dkhil, H., Mchich, R., \& Yassine, A. (2018). Storage yard management in container transshipment: Benchmarking methodology. In 2018 4th International Conference on Logistics Operations Management (GOL), 1-5.

Henesey, L. (2020). Multi-Agent Container Terminal Management. Retrieved from http://urn.kb.se/resolve?urn=urn:nbn:se:bth-00342.

Hildenbrandt, E., Saxena, M., Rodrigues, N., Zhu, X., Daian, P., Guth, D., Moore, B., Park, D., Zhang, Y., Stefanescu, A., \& Rosu, G. (2018). KEVM: A Complete Formal Semantics of the Ethereum Virtual Machine. 2018 IEEE 31st Computer Security Foundations Symposium (CSF). doi:10.1109/csf.2018.00022. 
Hu, W., Wang, H., \& Min, Z. (2014). A storage allocation algorithm for outbound containers based on the outer-inner cellular automaton. Information Sciences, 281, 147-171. doi:10.1016/j.ins.2014.05.022.

Hu, Z.H., Sheu, J.B., \& Luo, J.X. (2016). Sequencing twin automated stacking cranes in a block at automated container terminal. Transportation Research Part C: Emerging Technologies, 69, 208-227. doi: 10.1016/j.trc.2016.06.004.

Huang, Z., Yu, H., Chu, X., \& Peng, Z. (2017). A goal programming based model system for community energy plan. Energy, 134, 893-901. doi: 10.1016/j.energy.2017.06.057.

Imai, A., Nishimura, E., \& Papadimitriou, S. (2001). The dynamic berth allocation problem for a container port. Transportation Research Part B: Methodological, 35(4), 401-417. doi:10.1016/S0191-2615(99)00057-0.

Imai, A., Sasaki, K., Nishimura, E., \& Papadimitriou, S. (2006). Multi-objective simultaneous stowage and load planning for a container ship with container rehandle in yard stacks. European Journal of Operational Research, 171(2), 373-389. doi: 10.1016/j.ejor.2004.07.066.

Jamalnia, A., \& Soukhakian, M.A. (2009). A hybrid fuzzy goal programming approach with different goal priorities to aggregate production planning. Computers \& Industrial Engineering, 56(4), 1474-1486. doi: 10.1016/j.cie.2008.09.010.

Jiang, X., Lee, L.H., Chew, E.P., Han, Y., \& Tan, K.C. (2012). A container yard storage strategy for improving land utilization and operation efficiency in a transshipment hub port. European journal of operational research, 221(1), 64-73.

Jiang, X.J., \& Jin, J.G. (2017). A branch-and-price method for integrated yard crane deployment and container allocation in transshipment yards0 Transportation Research Part B: Methodological, 98, 62-75. doi: 10.1016/j.trb.2016.12.014

$\mathrm{Ku}, \mathrm{D} .$, \& Arthanari, T.S. (2016). Container relocation problem with time windows for container departure. European Journal of Operational Research, 252(3), 1031-1039. doi:10.1016/j.ejor.2016.01.055.

Lee, D.H., \& Chen, J.H. (2010). An improved approach for quay crane scheduling with non-crossing constraints. Engineering Optimization, 42(1), 1-15.

Legato, P., \& Mazza, R.M. (2001). Berth planning and resources optimisation at a container terminal via discrete event simulation. European Journal of Operational Research, 133(3), 537-547. doi:10.1016/S0377-2217(00)00200-9.

Legato, P., \& Monaco, M.F. (2004). Human resources management at a marine container terminal. European Journal of Operational Research, 156(3), 769-781. doi: 10.1016/S0377-2217(03)001346.

Luo, J., Wu, Y., \& Mendes, A.B. (2016). Modelling of integrated vehicle scheduling and container storage problems in unloading process at an automated container terminal. Computers \& Industrial Engineering, 94, 32-44. doi: 10.1016/j.cie.2016.01.010.

Maretto, L. (2020). A Decision Support System for the Storage Space Allocation Problem under the Effect of Disturbances: a Case of the Port of Arica (Chile). http://tesi.cab.unipd.it/64219/.

Martel, J.M., \& Aouni, B. (1998). Diverse imprecise goal programming model formulations. Journal of Global Optimization, 12(2), 127-138.

Mirzaee, H., Naderi, B., \& Pasandideh, S.H.R. (2018). A preemptive fuzzy goal programming model for generalized supplier selection and order allocation with incremental discount. Computers \& Industrial Engineering, 122, 292-302. doi: 10.1016/j.cie.2018.05.042.

Mokhtari, H., \& Hasani, A. (2017). A multi-objective model for cleaner production-transportation planning in manufacturing plants via fuzzy goal programming. Journal of Manufacturing Systems, 44, 230-242. doi: 10.1016/j.jmsy.2017.06.002. 
Oddoye, J.P., Jones, D.F., Tamiz, M., \& Schmidt, P. (2009). Combining simulation and goal programming for healthcare planning in a medical assessment unit. European Journal of Operational Research, 193(1), 250-261. doi: 10.1016/j.ejor.2007.10.029.

Poux, X., \& Aubert, P.M. (2018). Une Europe agroécologique en 2050 : une agriculture multifonctionnelle pour une alimentation saine. Enseignements d'une modélisation du système alimentaire européen, Iddri-AScA, Study $\mathrm{N}^{\circ} 09 / 18, \quad$ Paris, France, 78. https://www.iddri.org/sites/default/files/PDF/Publications/Catalogue\%20Iddri/Etude/201809 -ST0918-tyfa_0.pdf.

Rekik, I., Elkosantini, S., \& Chabchoub, H. (2015). Container stacking problem: a literature review. CIE45 Proceedings, Metz / France. https://www.researchgate.net/profile/Sabeur_Elkosantini/publication/294799315_Container_st acking_problem_a_survey/links/58cc59674585157b6dac0cb4/Container-stacking-problem-asurvey.pdf.

Rekik, I., Elkosantini, S., \& Chabchoub, H. (2018). A case based heuristic for container stacking in seaport terminals. Advanced Engineering Informatics, 38, 658-669. doi: 10.1016/j.aei.2018.08.016.

Romero, C. (1986). A survey of generalized goal programming (1970-1982). European Journal of Operational Research, 25(2), 183-191. doi: 10.1016/0377-2217(86)90084-6.

Sharif, O., \& Huynh, N. (2013). Storage space allocation at marine container terminals using ant-based control. Expert Systems with Applications, 40(6), 2323-2330. doi: 10.1016/j.eswa.2012.10.032.

Steenken, D., Voß, S., \& Stahlbock, R. (2004). Container terminal operation and operations research-a classification and literature review. OR spectrum, 26(1), 3-49.

Tan, C., He, J., \& Wang, Y. (2017). Storage yard management based on flexible yard template in container terminal. Advanced Engineering Informatics, 34, 101-113. doi:10.1016/j.aei.2017.10.003.

Ting, C.J., \& Wu, K.C. (2017). Optimizing container relocation operations at container yards with beam search. Transportation Research Part E: Logistics and Transportation Review, 103, 17-31. doi:10.1016/j.tre.2017.04.010.

Vis, I.F.A., \& de Koster, R. (2003). Transshipment of containers at a container terminal: An overview. European Journal of Operational Research, 147(1), 1-16. doi: 10.1016/S0377-2217(02)00293-X.

Woo, Y.J., \& Kim, K.H. (2011). Estimating the space requirement for outbound container inventories in port container terminals. International Journal of Production Economics, 133(1), 293-301. doi:10.1016/j.ijpe.2010.04.032.

Woo, Y.J., Song, J.H., \& Kim, K.H. (2016). Pricing storage of outbound containers in container terminals. Flex Serv ManufJ, 28(4), 644-668. doi: 10.1007/s10696-016-9245-7.

Yan, W., Huang, Y., Chang, D., \& He, J. (2011). An investigation into knowledge-based yard crane scheduling for container terminals. Advanced Engineering Informatics, 25(3), 462-471. doi:10.1016/j.aei.2011.03.001.

Yang, X., Low, J.M.W., \& Tang, L.C. (2011). Analysis of intermodal freight from China to Indian Ocean: A goal programming approach. Journal of Transport Geography, 19(4), 515-527. doi:10.1016/j.jtrangeo.2010.05.007.

Youssef, K.M., Scattergood, R.O., Murty, K.L., Horton, J.A., \& Koch, C.C. (2005). Ultrahigh strength and high ductility of bulk nanocrystalline copper. Applied Physics Letters, 87(9), 091904. doi:10.1063/1.2034122.

Yue, D., You, F., \& Snyder, S.W. (2014). Biomass-to-bioenergy and biofuel supply chain optimization: Overview, key issues and challenges. Computers \& Chemical Engineering, 66, 36-56. doi:10.1016/j.compchemeng.2013.11.016. 
Zhang, C., Liu, J., Wan, Y., Murty, K.G., \& Linn, R.J. (2003). Storage space allocation in container terminals. Transportation Research Part B: Methodological, 37(10), 883-903. doi: 10.1016/S01912615(02)00089-9.

Zhen, L. (2014). Container yard template planning under uncertain maritime market. Transportation Research Part E: Logistics and Transportation Review, 69, 199-217. https://doi.org/10.1016/j.tre.2014.06.011.

Zhuang, Z.Y., \& Hocine, A. (2018). Meta goal programing approach for solving multi-criteria de Novo programing problem. European Journal of Operational Research, 265(1), 228-238. doi:10.1016/j.ejor.2017.07.035.

Share - copy and redistribute the material in any medium or format Adapt - remix, transform, and build upon the material for any purpose, even commercially.

The licensor cannot revoke these freedoms as long as you follow the license terms.

Under the following terms:

Attribution - You must give appropriate credit, provide a link to the license, and indicate if changes were made.

You may do so in any reasonable manner, but not in any way that suggests the licensor endorses you or your use.

No additional restrictions

You may not apply legal terms or technological measures that legally restrict others from doing anything the license permits.

Journal of Sustainable Development of Transport and Logistics (ISSN: 2520-2979) is published by Scientific Publishing House "CSR", Poland, EU and Scientific Publishing House "SciView", Poland, EU

Publishing with JSDTL ensures:

- Immediate, universal access to your article on publication

- High visibility and discoverability via the JSDTL website

- Rapid publication

- Guaranteed legacy preservation of your article

- Discounts and waivers for authors in developing regions

Submit your manuscript to a JSDTL at https://jsdtl.sciview.net/ or submit.jsdtl@sciview.net 